\title{
Determination and Validation of the Project for Educational Research That Scales (PERTS) Survey Factor Structure
}

\author{
Janet Hanson (Corresponding author) \\ Department of Educational Leadership, Azusa Pacific University, Azusa (APU) \\ P.O. Box 7000, Rm 137, Azusa, CA 91702-7000, USA \\ Tel: 1-(626)-815-5375Ｅ-mail: jhason@apu.edu
}

Received: December 20, 2016 Accepted: January 24, $2017 \quad$ Published: January 29, 2017

doi:10.5296/jei.v3i1.10646ＵRL: http://dx.doi.org/10.5296/jei.v3i1.10646

\begin{abstract}
This study used exploratory factor analysis to test the factor structure of the Project for Educational Research That Scales (PERTS) instrument. Research that reports the reliability, construct validity, and factor structure of the PERTS scale is useful for interpreting the results from the use of the widely distributed survey and for suggesting interventions to develop an academic mindset in the classroom. Correlations and exploratory factor analyses were performed using pre-existing data from a medium-sized, rural school district, in a large southwestern state of the U.S. as self-reports from a sample of 2,908 students, in grades 3 through 8 , at three elementary and two middle schools. Results of the exploratory factor analysis confirmed the proposed four-factor structure. The PERTS survey demonstrated internal reliability on three of the four scales above the pre-determined indices of Cronbach's alpha $>.80$, with the exception of the individual mindset scale with a Cronbach's alpha of .772 .

Keywords: Academic mindset, Elementary and middle school classroom culture, PERTS scale, Survey validation

\section{Introduction}

This study empirically tested the factors of an academic mindset purported to be operationalized on the PERTS instrument including; a student's sense of belonging, relevance of the tasks required, a belief in one's ability to perform the classroom tasks (self-efficacy), and a belief in the malleability of one's intelligence, i.e. that one can grow one's intelligence through effort. When classroom teachers have reliable data collection instruments and understand the factors related to student choice to engage, teachers can provide psycho-social
\end{abstract}


supports within the classroom social organization and model behaviors that build relationships and collective efficacy in the classroom. Teachers can develop team activities, classroom structures, and social organization that support student autonomous choice to engage the learning process.

Osterman (2000) found variables within the school context and instructional methods that can be influenced by administrators and teachers and that develop academic mindsets in students (Blackwell et al., 2007). Academic mindsets are associated with behaviors that have large effects on student learning. Students with academic mindsets demonstrate academic behaviors of study, attendance, and homework completion (Farrington et al., 2012).

The Project for Education Research that Scales (PERTS) provides an example of how the influence of school context on academic mindset was studied (PERTS, 2015b). PERTS website describes the use of the PERTS scale as follows:

While supporting the dissemination of research-based innovations, PERTS gathers essential data on their outcomes. That data teaches us how to faithfully and sustainably grow the reach of these innovations and maximize their impact on educational equity (para. 4).

The concept of academic mindset is set in a framework of social cognitive learning theory (Bandura, 2001). Bandura (1989b) wrote self-efficacy results from one's experience in social interactions. A classroom's social organization differs from the structure and routines established by the teacher for management of behaviors and for instructional delivery. The formal structures and hierarchy exert external control on the students' behaviors in the classroom.

An individual must choose to engage new experiences that challenge one's existing knowledge structures in order to develop meaningful learning that can transfer to new situations (Novak, 2002). A person's sense of autonomy and control develops from experiencing a supportive social environment leading to positive experiences of individual development. Successful social interaction requires higher levels of cognitive development because of the complexity of interacting with diverse others (King \& Shuford, 1996).

Autonomous action is set in a framework of social cognitive theory, advanced by Bandura (2001). Bandura described three different ways people act on their world including; individual agency, proxy agency, and collective agency (p. 13). He emphasized the influence on one's belief in their power over their world resulting from the interactions between the individual and one's social environment.

Bandura (2001) wrote, “The essence of humanness is one's personal agency to operate within a context of sociocultural influences." Cognitive social theory describes personal agency as the ability to "make things happen by one's own actions." Self-efficacy is a core belief influencing behaviors according to the social cognitive theory. Psychosocial factors of belonging, task relevance (related to goal alignment), and individual mindset, contribute to the belief in one's ability to achieve individual goals. 
Teachers can develop healthy classroom cultures that promote academic mindsets through improving student autonomy. Balancing the roles between integration (system role) and individual role is a key variable for developing a flexible focus that allows students to shift from one perspective to another that best fits the context at the moment and promotes autonomous functioning (Hanson, in progress).

Proxy agency is sought when individuals need help obtaining resources, or managing the social environment. The individual may seek a proxy, or someone who has skills, resources, social capital, and power to act in one's behalf. In fact, individuals prefer proxy agency to individual agency because it can take more effort to master a skill and obtain resources and individual control than to gain control through the actions of others (Bandura, 2001).

Proxy agency is also demonstrated, and necessary, in the division of labor and in specialization. Proxy agency is evident in the classroom social organization when teachers provide classroom roles that build on student strengths and provide opportunity for students to contribute to the collective good. Advantages to the group and individuals accrue from the use of proxy agency when the group is organized for collective efficacy. Teachers can obtain trust from their followers when they act as proxy agents demonstrating classroom procedural justice and by making ethical decisions.

Promoting healthy collective action develops the students' sense of belonging and builds individual relationships. When teachers provide healthy psycho-social supports through healthy informal, relational, social organization students' sense of self-efficacy increases resulting in their choice to engage academic behaviors (Farrington et al., 2012).

The terms self-efficacy and collective efficacy describe important concepts related to improving student success and creating successful learning experiences in the classroom. Self-efficacy is domain specific (DSSE) and can be measured as a students' belief in their ability to be successful on classroom tasks. Two components make up the concept of self-efficacy. First, one can believe the classroom task can be accomplished by effort. Secondly, a belief must exist that sufficient resources, time, innate ability, and social supports are present to accomplish the task if the student puts in the effort in the present situation and in future contexts (Goddard, 2002).

\subsection{Purpose Statement}

This paper proposes to test the factor structure and reliability of the PERTS instrument and to test the relationship between psycho-social variables found in the literature under the description of academic mindsets in the classroom. Understanding classroom context in relationship to developing student engagement is a necessary part of successful teaching. Historically, assessment measures in schools have largely focused on cognitive variables demonstrating learning outcomes of students and school effectiveness. Current research seeks to develop valid conclusions drawn from reliable data collection in the area of psycho-social variables shown to support student learning, including the construct of an academic mindset in the classroom (Farrington et al., 2012).

The PERTS instrument purports to quantify the construct of an academic mindset comprised 
of four factions including: individual mindset, sense of belonging in the classroom, task relevance, and student self-efficacy on classroom tasks (PERTS, 2015a). Research suggests that students with high academic mindsets engage academic behaviors such as attending class, homework completion, organizing work, and studying leading to improved learning outcomes (para. 5). The PERTS research team's mission statement and purpose for designing the PERTS scale is "to improve the equity of learning outcomes by bridging the gap between cutting-edge research and implementation practices ...” (PERTS, 2015b, para. 2).

\subsection{Problem Statement}

Rachel Marie Herter, PERTS Lab, Dept. of Psychology at Stanford University, in a personal communication (February 7, 2016) explained the current version of the PERTS scale gives data at the classroom level, places students into different category bins, and is not useful for comparing students between surveys. For teachers, who use the PERTS instrument, provided free on the PERTS website, an understanding of the relationships between the underlying constructs, purported to be quantified in the PERTS scale, is important for an accurate interpretation of the scale results, for drawing valid conclusions, and for determining classroom specific interventions. Therefore, further study of the relationships between the factors of the PERTS instrument and subscale reliabilities is warranted.

\subsection{Research Questions}

The overarching research questions for this study included:

What is the factor structure of the PERTS instrument?

Are the scale reliability indices of the PERTS instrument within predetermined acceptable parameters?

Practical interventions for supporting student learning and a summary and conclusion of the results of this study will be provided, discussing the importance of understanding the use of psycho-social factors in the social context of the classroom. Psycho-social factors are reported to provide additional paths to help students develop personal agency to engage in academic behaviors resulting in learning and growth (Farrington, Roderick, Allensworth, Nagaoka, Seneca-Keyes, Johnson \& Beechum, 2012). Following are a list of definitions of terms used on the PERTS scale and in this paper.

\subsection{Definitions}

Academic mindset. Farrington et al. (2012) described academic mindset as the "beliefs, attitudes, or ways of perceiving oneself in relation to learning and intellectual work that support academic performance" (p. 28). The four distinct academic mindsets include beliefs of belonging; the ability one can grow through effort; that one can succeed; and the work required has value.

Individual mindset. (Items 1-3 reversed scored) has been described as "the way in which children interpret human behavior and their beliefs about the stability of human traits," one's individual mindset belief has been shown to affect a student's attitude and beliefs about their 
ability to perform, also referred to as self-efficacy on classroom tasks (Heyman \& Dweck, 1998, p. 391; $2002 \& 2008)$.

Sense of belonging. (Items 4-7) Goodenow and Grady (1993) in Ma (2003) defined sense of belonging as "the extent to which students feel personally accepted, respected, included, and supported in the school social environment" (p. 340).

Task relevance. (Items 8-11) “A student's sense that the subject matter he or she is studying is interesting and holds value. Value can be variously defined as the importance of doing well on a task (attainment value); gaining enjoyment by doing a task (intrinsic value); or serving a useful purpose or meeting an end goal that is important by completing a task (utility value)" (Eccles et al., 1983 in Farrington et al., 2012, p. 10).

Self-efficacy. (Items 12-15) "A mechanism of personal agency, the belief about one's ability to exercise control over other events that affect their lives." Self-efficacy beliefs affect thought patterns and influence one's choice of goals and commitment to them (Bandura, 1989, p. 1175). Self-efficacy is an expectancy theory. A student with high self-efficacy for a certain task, would expect to be able to accomplish that task within the given context.

\section{Literature Review}

Dweck's (1986) development of the concept of individual personality theories of fixed and growth mindset was deeply rooted in the framework and history of social cognitive theory. This present study tests a Likert-style instrument purported to quantify variables found in the theory of academic mindsets; adding to the individual mindset learning theory by collecting data at the group/classroom level (Farrington, et al., 2012).

\subsection{Psycho-social Influences on Learning}

\subsubsection{Conscious and Unconscious Processes Influencing Learning}

Some researchers are suggesting new models for thinking about the brain and new models for describing how we learn. These newer models usually include learning as socially constructed and dependent on both implicit and explicit processes of knowing. This distinction becomes a foundation for understanding Bandura's (2001) social cognitive theory and its triadic model of reciprocal influence including: the human cognition, one's environment, and the influence of social modeling on the behavior of the learner.

\subsubsection{Behaviorism}

Bandura's experiments were among the first to report the powerful influence of nurture, or social influence, on individual learning. Prior to Bandura's research, educational models of learning focused largely on behaviorism. Pavlov's experiments with stimulus response procedures to develop salivation in dogs is well known and supports the teaching models of many educational curriculum and classroom management models. Stimulus response theory suggested humans learned through a series of rewards and punishments, without reference to cognitive choice or the influence of one's social group. The behaviorists' experiments were performed using animals, not humans. Some researchers felt studying cognition was not 
possible because the mind could not be seen; so they focused on researching observable behaviors.

\subsubsection{Social Cognitive Theory}

Bandura (2001) explained, “... the essence of humanness" is one's personal agency to operate within a context of sociocultural influences (p. 1). The development of the individual depended on positive social interactions resulting in one's belief in the power to successful act on one's world. An individual's thoughts, feelings, and physiology also were shown to influence how one chooses to respond to life's challenges. Within a classroom context, students develop beliefs about their ability to be successful on tasks, their social identity within the classroom context, sense of belonging, and a belief in their ability to grow and learn. The purported factors of an academic mindset compare favorably with the concepts of individual self-efficacy and collective efficacy. Bandura described core features of an individual's choice to act including; the ability to plan (intentionality), set future goals (forethought), motivation and self-monitoring (self-reactiveness), and efficacy (self-reflectiveness). The social context has been shown to have a significant influence on an individual's beliefs, attributes, interests and resulting behaviors and choices (p. 13).

\subsection{The Classroom as a System}

According to system's theory, a primary activity of a classroom teacher would be to promote the development of the classroom as a learning organization. Senge (1990) explained:

... people are agents, able to act upon the structures and systems of which they are a part. All the disciplines are, in this way, 'concerned with a shift of mind from seeing parts to seeing wholes, from seeing people as helpless reactors to seeing them as active participants in shaping their reality, from reacting to the present to creating the future' ( $\mathrm{p}$. 69).

Senge's system theories points to the important influence of the teacher on the culture of the classroom and the impact of providing team opportunities for students to develop social identities, positive learning experiences, and shared beliefs. Open systems engaging school structures theory explains similar variables influencing student engagement. Yeo (2005) claimed organizational learning occurred in three stages: 1) the individual level involving non-routine tasks and is resistant to change, 2) at the team level involving non-routine problem-solving with opportunities for action, and 3) the organization level involving complex solutions by the collective through changing the external environment (p. 379). Open systems learning outcomes and Senge's types of learning that occurs at the three levels as shown in Table 1. 
Table 1. Influences on the types of learning from three levels of organizing described in Senge's (2000) Five Disciplines

\begin{tabular}{|l|l|l|l|}
\hline Stages of Learning & \multicolumn{1}{|c|}{ Level I } & \multicolumn{1}{c|}{ Level II } & \multicolumn{1}{c|}{ Level III } \\
\hline Senge's Disciplines & $\begin{array}{l}\text { Individual mental } \\
\text { models and personal } \\
\text { mastery }\end{array}$ & $\begin{array}{l}\text { Team learning } \\
\text { changes how people } \\
\text { think. The focus is on } \\
\text { the manager }\end{array}$ & $\begin{array}{l}\text { Systems thinking, } \\
\text { developing a shared } \\
\text { vision, and creating a } \\
\text { way of life. }\end{array}$ \\
\hline Open Systems & $\begin{array}{l}\text { Individual control over } \\
\text { environment, } \\
\text { individual's belief in the } \\
\text { group's ability }\end{array}$ & $\begin{array}{l}\text { Collegial teams with } \\
\text { open communication }\end{array}$ & $\begin{array}{l}\text { System changes include } \\
\text { group decision making } \\
\text { and culture changes } \\
\text { supported by the leader }\end{array}$ \\
\hline School Mindset Culture & $\begin{array}{l}\text { Individual belief in the } \\
\text { faculty's ability to help } \\
\text { all students grow and } \\
\text { learn }\end{array}$ & $\begin{array}{l}\text { Team collaborations } \\
\text { with open } \\
\text { communication }\end{array}$ & $\begin{array}{l}\text { System changes through } \\
\text { shared leadership, } \\
\text { common goals, and a } \\
\text { school-wide plan to get } \\
\text { there }\end{array}$ \\
\hline $\begin{array}{l}\text { Academic Mindset } \\
\text { In the Classroom }\end{array}$ & $\begin{array}{l}\text { Self-efficacy } \\
\text { Individual Mindset }\end{array}$ & Sense of Belonging & Task Relevance \\
\hline
\end{tabular}

\subsubsection{Comparing Variables of an Academic Mindset}

Consistent with social cognitive theory and Senge's system theory, a student's academic mindset is developed from experiences in the classroom on the individual, team, and classroom level. Researchers described academic mindsets as ways students think of themselves that make them want to learn (Farrington et al., 2012, p. 9). Figure 1 shows a comparison of variables contributing to learning at the different levels of organization including the variables operationalized on the academic mindset scale. 

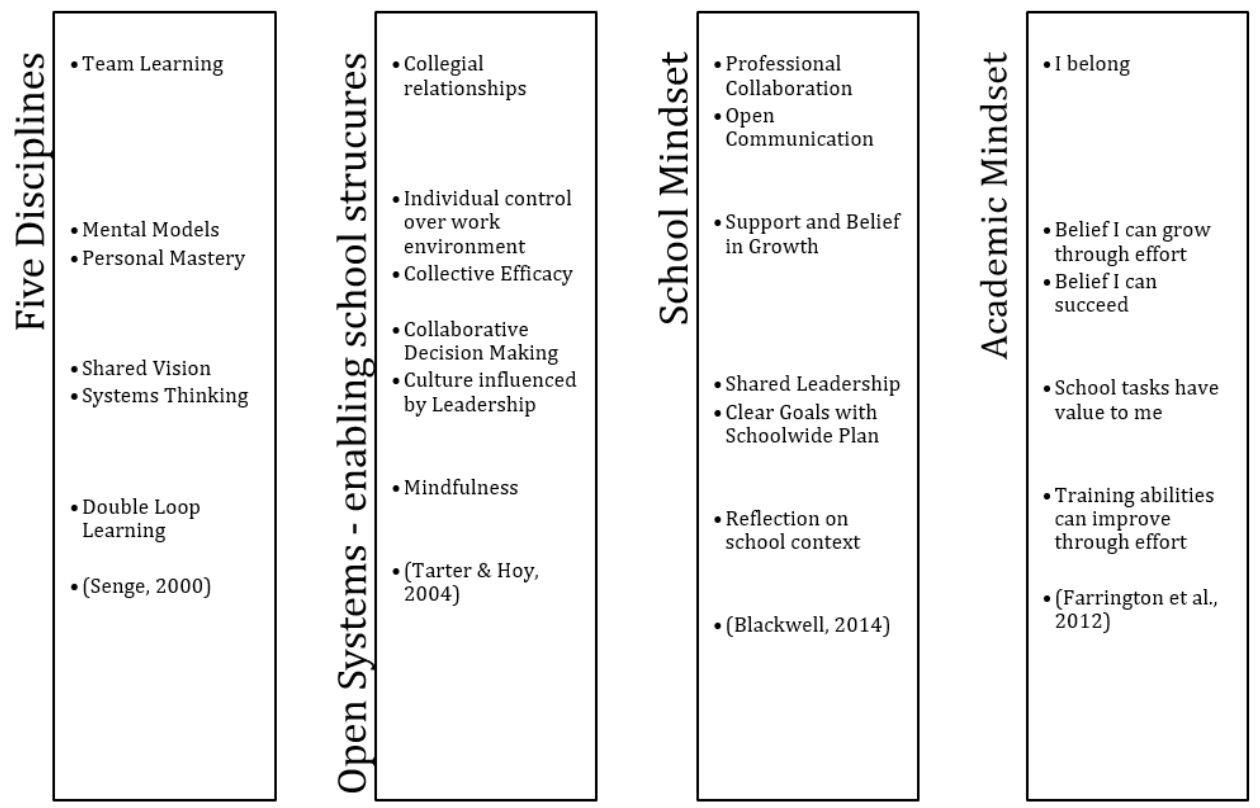

Figure 1. Comparable and contrasting concepts with mindset constructs

\subsubsection{Individual Level}

A teacher can embed multiple opportunities for students to master the tasks required while providing sufficient psycho-social support through positive feedback and specific tasks for improvement. Allow the students to practice the behavior over many trials until they master the behavior on their own. Where necessary, model and provide explicit instruction on how to manage one's own stress responses

\subsubsection{Team Level}

Teachers can develop a sense of belonging for students in the classroom by providing opportunities for team collaboration and identifying each student's role in the group. Be explicit and clear. Match the students' strengths and personal role identities with the team roles. Allow students to give feedback on their experiences in the group and then respond to their suggestions. Ensure the group activity develops positive interaction with others. Sense of belonging has been connected with developing positive relationships (Deci \& Ryan, 1994). Use double loop learning strategies (Argyris \& Schön, 1978).

\subsubsection{Classroom Level}

Modeling by the classroom teacher influences the classroom system and indirectly the individual students. Modeling has been shown to be an effective way to build positive classroom culture and promote student self-efficacy. Aligning individual students' goal with the classroom level goals has been shown to develop individual self-efficacy and group collective efficacy (Bandura, 2001; Dweck, 2010; Hanson, 2015). When the leader's formal (position) is integrated with the informal (relational) position one develops a sense of “... moral authority on their subordinates by establishing synchrony in their words and actions; 
the rest of the structure and processes of the organization also get aligned for it, thus creating a robust and transparent culture" (Sidik, 2013, slide \# 25).

\subsection{PERTS Factors}

A review of the literature in the areas of mindset, meaningful learning, theories of mind, and psycho-social factors contributing to student engagement revealed a common element of autonomous action within a social context. Student autonomy develops from the following student experiences: feeling a sense of belonging and social identity with supportive others in the classroom; being an inherent part of the process of reciprocal sense making; when classroom goals are aligned with the students' personal goals and values; opportunities are provided to take initiative; and one's personal values are embedded in the classroom tasks required creating a feeling of personal and life relevance. The concept of academic mindset adds to the individual mindset construct. Students with higher academic mindsets demonstrate greater levels of academic behaviors such as study, attendance, and homework completion (PERTS, 2015a, para. 5).

\subsubsection{Self-Efficacy}

Providing feedback through positive social relationships and opportunities to practice tasks with others are ways teachers can develop self-efficacy in students. A review of the literature describes four variables contributing to the development of self-efficacy: mastering a task, observing others successfully performing the task, being told by valued others that one can be successful, and developing one's ability to manage physiological and psychological stress states (Versland, 2009). .

\subsubsection{Sense of Belonging}

Research suggests increases in motivation, engagement in academic behaviors, and dedication to the school are explained by students' sense of belonging (Osterman, 2000). In Maslow's (1943) hierarchy of needs theory, belonging is considered a basic human need. Schwarz (1990) included sense of belonging as part of security in his model of motivational types of values. Developing a sense of safety in the classroom requires the teacher to provide equitable and just classroom systems and processes. A sense of social identity begins with interacting at the team level. The interventions for an academic classroom mindset culture include teachers/leader development of skills for providing psycho-social supports such as relationship building, acknowledgement of the individuals' personal identity, providing role identity in teams, supportive feedback in a timely and positive fashion.

\subsubsection{Task Relevance}

A next step in the process of developing academic mindsets in students is to provide real world educational opportunities for students and connect these to students' prior learning. A teacher can develop task relevance by providing a purpose for the activities that the students can understand and aligning classroom goals with the student's individual goals. Connecting with students develops an understanding of their personal interests and opportunities to align the classroom tasks to students' values. Provide real world educational opportunities for 
students to develop a sense of task relevance to life experiences. Organizational values and norms can differ from individual norms, yet, individuals can agree to participate in the overall activities of the group or internalize the goals of the group.

\subsubsection{Individual Mindset}

Mindset as a psycho-social construct compares favorably with self-efficacy described as “... a mechanism of personal agency, the belief about one's ability to exercise control over other events that affect their lives" (Bandura, 1989, p. 1175). While mindset and self-efficacy are similar in they influence one's belief in personal agency, they differ in that mindset is a belief about the malleability of one's traits, whereas self-efficacy is a belief in one's abilities to perform a task. One's mindset has an indirect influence on the successful academic outcomes through the influence it has on developing one's self-efficacy beliefs.

However, research suggests the individual's mindset has little correlation with the group level mindset culture in schools (Hanson, 2017).

\section{Methods}

This study used a quantitative research design and existing data from a mid-size, rural school district in a large southwestern state. The school district collected data on the schools' cultures and climate for use in setting Local Control and Accountability Planning (LCAP) goals.

\subsection{Data Sources and Participants}

The school district collected LCAP survey data during the month of April, 2016, using a variety of Likert-style surveys delivered to students, grades 3 through 8 , $(\mathrm{n}=2,908 ; 84 \%$ response rate) in the classroom at three elementary schools and two middles schools; faculty participants included teachers, grades TK-8, $(\mathrm{n}=224)$, other certificated personnel $(\mathrm{n}=9)$, and administrators $(\mathrm{n}=11)$.

\subsection{Instrumentation}

This study tested data collected by the district from LCAP climate and culture surveys and included a brief demographic questionnaire plus 15-items of the Project for Educational Research the Scales (PERTS) instrument including four sub-scales; individual mindset (3 items), sense of belonging in the classroom (4 items), task relevance (4 items), and self-efficacy on classroom tasks (4 items). Respondents self-reported their agreement with scale items by providing ratings on a Likert-style scale ranging from $1=$ Strongly Disagree, 2 $=$ Disagree, $3=$ Somewhat Disagree, $4=$ Somewhat Agree, $5=$ Agree, to $6=$ Strongly Agree .

No reliability data was available for the scales (Rachel Marie Herter at PERTS lab, Inc., February 8, 2016). However, this study empirically tested the scale reliabilities using the predetermined indicator of Cronbach's alpha $>.80$ as an acceptable level for internal reliability of a widely used scale (Nunnally, 1978).

A variety of studies have been performed and reported in the literature demonstrating concept validity of the operationalized constructs on the PERTS scale (Farrington et al., 2012). The 
scale has strong face validity being currently used in large scale studies. The Appendix provides the PERTS scale items.

\subsection{Analyses}

The data collected in this study was evaluated for normality, skewness, and kurtosis using quantitative analytical software SPSS, 23 (IBM, 2015). The mean value of students' perceptions on their level of individual mindset, sense of belonging in the classroom, task relevance, and self-efficacy were calculated and correlation analysis was performed between the scales. The following range of indices, as average arithmetic means in three categories, is provided to create a low, medium and high range as a method to interpret the data: Low $=$ 1.00-2.67; Moderate $=2.68<\mathrm{x}<4.35$; High $=4.36-6.0$.

An exploratory factor analysis investigated the psychometric properties of the four scales including reliability statistics and other information on validity testing. The determination of model fitness was developed from factor loadings, validity, reliability and normality. These values were used to determine whether the scales were valid for measuring the level of psycho-social variables in educational settings in the population under study.

\section{Results}

\subsection{Data Analysis}

Data analyses included statistical tests using SPSS, Version 23 statistical software (IBM, 2015) to determine if the data fit a normal distribution and was considered reasonable for parametric analyses. All items tested were within acceptable limits \pm 2 (Trochim \& Donnelly, 2006; Field, 2000, 2009; Gravetter \& Wallnau, 2014).

\subsubsection{Correlations}

A bivariate correlation analysis was performed and significant relationships were found. However, results for the Bartlett's Test of Sphericity was found to be significant indicating that the items, although correlated, were not correlated so highly as to produce an identity matrix preventing the factor analysis from successfully reducing the data into interpretable factors. This was consistent based upon the item descriptions and the theory. An exploratory factor analysis was performed using SPSS, maximum likelihood extraction and oblique rotation methods.

\subsubsection{Exploratory Factor Analysis}

Four scales were revealed as predicted with internal scale reliability ratings above preset indices of .80 with the exception of the individual mindset scale at .772 . The EFA yielded a four-factor solution using maximum likelihood extraction and Varimax rotation method. Each of the four scales consisted of at least three items, exhibited factor loadings $<.80$ and $>.30$ and had items that were minimally cross-loaded with items in other factors (Brown, 2009; Field, 2009; Gravetter \& Wallnau, 2014). Discriminant validity between scales was shown by items loading together above .3 on the factor and no cross-loadings, with the exception of items number 8, 9, and 4; however, the difference between correlations exceeded .2. Stevens 
(2002) suggests that item loadings should differ by at least .200 to be interpreted as not cross-loaded with other factors. Table 2 shows results of the EFA on PERTS factors.

Table 2. Individual item factor loadings, significance, percentage of variance, and eigenvalues for items on the PERTS scale

\begin{tabular}{|c|c|c|c|c|c|c|}
\hline \multirow[b]{2}{*}{ Items } & \multicolumn{4}{|c|}{ Scales } & \multirow[b]{2}{*}{$M$} & \multirow[b]{2}{*}{$S D$} \\
\hline & $\begin{array}{l}\text { Sense of } \\
\text { Belonging } \\
\text { (SB) }\end{array}$ & $\begin{array}{l}\text { Self- } \\
\text { Efficacy } \\
\text { (SE) }\end{array}$ & $\begin{array}{l}\text { Task } \\
\text { Relevance } \\
\text { (TR) }\end{array}$ & $\begin{array}{l}\text { Individual } \\
\text { Mindset } \\
\text { (IM) }\end{array}$ & & \\
\hline 6. I feel comfortable in this class. & .773 & .187 & .251 & -.029 & 4.88 & 1.233 \\
\hline 5. I feel respected in this class. & .703 & .156 & .204 & -.017 & 4.62 & 1.313 \\
\hline 4. I feel like I belong in this class. & .624 & .213 & .307 & -.001 & 4.96 & 1.240 \\
\hline $\begin{array}{l}\text { 7. I feel like I can be myself in this } \\
\text { class. }\end{array}$ & .575 & .214 & .212 & .014 & 4.48 & 1.479 \\
\hline $\begin{array}{l}\text { 13. I can do well on tests, even when } \\
\text { they're difficult. }\end{array}$ & .139 & .779 & .129 & -.091 & 4.39 & 1.311 \\
\hline $\begin{array}{l}\text { 14. I can master the hardest topics in } \\
\text { my class. }\end{array}$ & .139 & .756 & .112 & -.124 & 3.99 & 1.437 \\
\hline $\begin{array}{l}\text { 12. I can earn an A or top grade in this } \\
\text { class. }\end{array}$ & .240 & .649 & .167 & -.105 & 4.92 & 1.225 \\
\hline $\begin{array}{l}\text { 15. I can meet all the learning goals } \\
\text { my teacher(s) set. }\end{array}$ & .281 & .584 & .270 & -.028 & 4.73 & 1.233 \\
\hline $\begin{array}{l}\text { 11. What we learn in this class is } \\
\text { necessary for success in the future. }\end{array}$ & .163 & .121 & .757 & .013 & 4.76 & 1.234 \\
\hline $\begin{array}{l}\text { 10. Working hard in this class matters } \\
\text { for success in my future. }\end{array}$ & .214 & .174 & .714 & -.048 & 4.97 & 1.195 \\
\hline $\begin{array}{l}\text { 9. This class teaches me valuable } \\
\text { skills. }\end{array}$ & .317 & .171 & .631 & -.017 & 4.95 & 1.147 \\
\hline $\begin{array}{l}\text { 8. My class gives me useful } \\
\text { preparation for what I plan to do in } \\
\text { life. }\end{array}$ & .301 & .168 & .589 & .000 & 4.44 & 1.386 \\
\hline $\begin{array}{l}\text { 2. Your intelligence is something } \\
\text { about you that you can't change very } \\
\text { much. }\end{array}$ & -.010 & -.105 & .002 & .787 & 2.79 & 1.579 \\
\hline $\begin{array}{l}\text { 3. You have a certain amount of } \\
\text { intelligence, and you really can't do } \\
\text { much to change it. }\end{array}$ & -.024 & -.072 & -.026 & .765 & 2.56 & 1.519 \\
\hline
\end{tabular}




\begin{tabular}{|l|l|l|l|l|l|l|}
\hline $\begin{array}{l}\text { 1. You can learn new things, but you } \\
\text { can't really change your basic } \\
\text { intelligence/how smart you are. }\end{array}$ & .009 & -.066 & -.007 & $\mathbf{. 6 3 0}$ & 3.06 & 1.575 \\
\hline Percent of Variance & 31.765 & 11.563 & 7.030 & 5.051 & & \\
\hline Eigenvalue & 5.208 & 2.176 & 1.477 & 1.179 & & \\
\hline Cronbach alpha & .820 & .830 & .820 & .772 & & \\
\hline
\end{tabular}

\subsubsection{Cross-Tabs}

Statistical analysis was performed to explore the interdependence of the demographic data variables and to identify statistically significant differences $(p<.05)$. One-way ANOVA analysis was used to compare the category means and determine any significant differences between groups that may affect the ability to generalize the results. Significant variations in the sample data were noted between the following categories:

Ethnic classification (self-selected by student respondents). The student self-efficacy (SE) mean scores revealed significant differences between ethnic classifications using a one-way $\operatorname{ANOVA}\left(F_{(9,2,898)}=3.030, p=.001\right)$.

Gender classification showed a negative relationship with student belonging and task relevance. A positive relationship existed between ethnicity and gender. Gender had no significant effect on the regression outcome and was removed from the analysis. Table 3 shows the correlations between classifications and scales of the PERTS survey instrument.

Table 3. Component correlations matrix for PERTS scale including gender and ethnicity

\begin{tabular}{|l|l|l|l|l|l|l|}
\hline & $\begin{array}{l}\text { Individual } \\
\text { Mindset }\end{array}$ & $\begin{array}{l}\text { Sense of } \\
\text { Belonging }\end{array}$ & $\begin{array}{l}\text { Task } \\
\text { Relevance }\end{array}$ & Self-efficacy & Gender & Ethnicity \\
\hline Individual Mindset & 1 & & & & & \\
\hline Sense of Belonging & $.043^{*}$ & 1 & & & & \\
\hline Task Relevance & $.046^{*}$ & $.551^{* *}$ & 1 & & & \\
\hline Self-efficacy & $.183^{* *}$ & $.466^{* *}$ & $.413^{* *}$ & 1 & & \\
\hline Gender & -.001 & $-.053^{* *}$ & $-.071^{* *}$ & -.024 & 1 & \\
\hline Ethnicity & -.035 & -.036 & .018 & $-.051^{* *}$ & $.044^{*}$ & 1 \\
\hline
\end{tabular}

Note. ${ }^{* *} p<.05,{ }^{* *} p<.01, n=2,905 ;{ }^{* *} p<.01$; level (2-tailed).

\subsubsection{Discriminant Validity}

A one-way ANOVA comparing the PERTS scale classroom mean scores between school 
levels was run to determine the ability of the PERTS data results to discriminate between groups. Table 4 shows the mean, standard deviation, and classroom sample for elementary and middle school levels.

Table 4. ANOVA results and Pearson Correlations between school building levels

\begin{tabular}{|l|l|l|l|l|}
\hline Factor & $M$ & $S D$ & Pearson's Coefficient (one-tailed) & $N$ \\
\hline Elementary** & 4.6502 & .26516 & $<.001$ & 70 \\
\hline Middle** & 4.4650 & .32376 & $<.001$ & 50 \\
\hline Total & 4.5784 & .74745 & & 120 \\
\hline
\end{tabular}

Note. ${ }^{* *} p<.05,{ }^{* *} p<.01, n=2,905 ;{ }^{* *} p<.01$; level (2-tailed).

\section{Summary and Conclusion}

This study provides additional empirical evidence for the use of a reliable scale for collecting research-based data on student psycho-social factors in the classroom context. The results of the EFA yielded a multi-dimensional, four-factor construct of academic mindset as operationalized on the PERTS instrument. The four subscales met the criteria for convergent validity with item loadings above .30 for each factor and divergent validity with more than .20 difference in loadings between item loadings of other factors.

\subsection{Research Questions}

The following sections provide a discussion of how the overarching research questions of this study were answered using results from empirical tests of the data collected on the PERTS scale in three elementary schools and two middles schools $(\mathrm{n}=2,908)$ in a rural district in a large southwestern state of the United States.

\subsubsection{Research Question \#1}

The first research question of this study, "What is the factor structure of the PERTS instrument?" was answered by the results of exploratory factor analyses revealing the PERTS instrument measures a multi-dimensional, four-factor structure of a classroom academic mindset. The results of this study suggest the PERTS scale represents the factors it purports to measure and may be used by classroom teachers as a reliable means to collect research-based data on their students' academic mindset culture in the classroom.

\subsubsection{Research Question \#2}

The study results answered question \#2, "Are the scale reliability indices of the PERTS instrument within predetermined acceptable parameters?" revealing only three of the four PERTS sub-scales had internal reliability above the predetermined indices. The individual mindset scale was below .80 and was considered potentially unreliable for a scale that is widely 
used. The individual mindset scale may not provide consistently accurate measurements of the students' self-reports of their perceptions of this construct. Total scale reliability index was Cronbach's alpha $=.801$.

\subsection{Conclusion}

The use of the PERTS survey instrument provides data to make valid decisions on the factors; student self-efficacy in the classroom, classroom task relevance, and student sense of belonging in the classroom. The data collected on these sub-scale are useful to provide growth markers toward meeting annual goals to improve school and classroom cultures. The measures obtained of these operationalized PERTS survey factors of student non-cognitive variables can be used as evidence of teachers' strategies to support student psychosocial needs, shown necessary to persist in school to graduation. The sub-scale for individual mindset was below preset indices for reliability and teachers should exercise caution when using the individual subscale results to inform classroom academic mindset interventions.

\subsection{Implications}

The results of this study have important implications for facilitating student learning as well as increasing teacher effectiveness. Teachers can use the results of this survey to reflect on their professional behaviors and classroom methods. Challenging one's assumptions is a beginning to the process of making effective changes and recognizing areas indicated for personal and professional development goals. The PERTS scale may also be used to evidence growth on goals and as a data source for accountability measures and setting LCAP classroom, school, and district level goals related to culture and climate, meeting the informing program development to meet the needs of diverse student populations, and to inform administrator and teacher professional development plans.

\subsection{Recommendations for Further Research}

Future studies might include qualitative interviews of students to develop a rich, thick, understanding of their experiences in the classroom and how they perceive the scale constructs of the PERTS survey instrument. Further exploration of the operationalized construct of individual mindset included on the scale is warranted, as the scale does not provide internal reliability for measuring this construct, according to the preset indices used in this study. Reliable scales are necessary to draw valid conclusions from the data provided. According to the results of a calculation performed, provided in Nunnally (1978), an additional four operationalized items with similar reliability are necessary in order to raise the individual mindset sub-scale, included on the PERTS scale, to the desired reliability indices of Cronbach's alpha score $>.80$ (p. 244).

\section{Acknowledgements}

A recognition and appreciation is extended to Dr. Arthur Bangert, associate professor, Montana State University, Bozeman, for his role in reviewing the statistical results and presentation provided in the methods section of this paper. 


\section{References}

Argyris, C., \& Schön, D. (1978). Organizational learning: A theory of action perspective. Reading, Mass: Addison Wesley.

Bandura, A. (1989). Regulation of cognitive processes through perceived self-efficacy. Developmental Psychology, 25(5), 729-735. https://doi.org/10.1037/0012-1649.25.5.729

Bandura, A. (1994). Self-efficacy. In V. S. Ramachaudran (Ed.), Encyclopedia of human behavior (Vol. 4, pp. 71-81). New York: Academic Press. [Reprinted in H. Friedman (Ed.), Encyclopedia of mental health. San Diego: Academic Press, 1998].

Bandura, A. (2001). Social cognitive theory: An agentic perspective. Annual Review of Psychology, 52, 1-26. https://doi.org/10.1146/annurev.psych.52.1.1

Bandura, A., Ross, D., Ross, S., \& Webb, D. (2013). Psychology classics all psychology students should read: The bobo doll experiment. CreateSpace Independent Publishing Platform.

Blackwell, L. S., Trzesniewski, K. H., \& Dweck, C. S. (2007). Implicit theories of intelligence predict achievement across an adolescent transition: A longitudinal study and an intervention. Child Development, 78, 246-263. https://doi.org/10.1111/j.1467-8624.2007. 00995.x

Deci, E. L., \& Ryan, R. M. (1994). Promoting self-determined education. Scandinavian Journal of Educational Research, 38, 3-14. https://doi.org/10.1080/0031383940380101

Delaney, S., Dweck, C., Murphy, M., Chatman, J., \& Kray, L. (January 1, 2015). New study findings: Why fostering a growth mindset in organizations matters. Retrieved March 15, 2015, from http://senndelaney.com/SD_growthmindsetstudy.html

Dweck, C. (1986). Motivational processes affecting learning. American Psychologist, 41(10), 1040-1048. https://doi.org/10.1037/0003-066X.41.10.1040

Dweck, C. S. (2010). Mind-sets and equitable education. Principal Leadership (pp. 26-29). Retrieved from http://www.principals.org/Content.aspx?topic=61219

Farrington, C., Roderick, M., Allensworth, E., Nagaoka, J., Seneca-Keyes, T., Johnson, D., \& Beechum, N. (June 1, 2012). Teaching adolescents to become learners: The role of noncognitive factors in shaping school performance. Chicago consortium on Chicago school research. Retrieved December 10, 2016, from https://consortium.uchicago.edu/ publications/teaching-adolescents-become-learners-role-noncognitive-factors-shaping-school

Field, A. (2000). Discovering statistics using SPSS for windows. London-Thousand OaksNew Delhi: Sage publications.

Field, A. (2009). Discovering statistics using SPSS. London: SAGE.

Goddard, R. D. (2002). A theoretical and empirical analysis of the measurement of collective efficacy: The development of a short form. Educational and Psychological Measurement, 93, 
467-476. https://doi.org/10.1177/0013164402062001007

Gravetter, F., \& Wallnau, L. (2014). Essentials of statistics for the behavioral sciences (8th ed.). Belmont, CA: Wadsworth.

Hanson, J. (2017). Testing the difference between school level and academic mindset in the classroom: Implications for developing student psycho-social skills in secondary school classrooms. Journal of Educational Issues, 3(1), 44-63. http://dx.doi.org/10.5296/ jei.v3i1.10479

Hanson, J. L. (2015). Determination and validation of the "What's My School Mindset?" instrument factor structure (Order No. 3722197). Dissertations \& Theses at Montana State University: ProQuest Dissertations \& Theses Global.

Heyman, G., \& Dweck, C. (1998). Children's thinking about traits: Implications for judgments of the self and others. Child Development, 64(2), 391-403. https://doi.org/10.1111/ j.1467-8624.1998.tb06197.x https://doi.org/10.2307/1132173

IBM Corp. (2015). IBM SPSS Statistics for MacIntosh (Version 23.0). Armonk, NY: IBM Corp.

King, P., \& Shuford, B. (1996). A multicultural view is a more cognitively complex view: Cognitive development and multicultural education. American Behavioral Scientist, 40(2), 153-164. http://dx.doi.org/10.1177/0002764296040002006

Loewenthal, K. M. (2004). An introduction to psychological tests and scales (2nd ed.). Hove, UK: Psychology Press.

Ma, X. (2003). Sense of belonging to school: Can schools make a difference? Journal of Educational Research, 96(6), 1-9. http://dx.doi.org/10.1080/00220670309596617

Maslow, A. H. (1943). Motivation and personality. New York: Harper \& Row.

Novak, J. (2002). Meaningful learning: The essential factor for conceptual change in limited or inappropriate propositional hierarchies leading to empowerment of learners. Science Education, 86(4), 548-571. https://doi.org/10.1002/sce.10032

Nunnally, J. C. (1978). Psychometric theory (2nd ed.). New York: McGraw-Hill.

Osterman, K. F. (2000). Students' need for belonging in the school community. Review of Educational Research, 70(3), 323-367. https://doi.org/10.3102/00346543070003323

Pavlov, I. P. (1927). In G. V. Anrep (Trans.), Conditioned reflexes. London: Oxford University Press.

PERTS. (2015a). Academic Mindsets Assessment. Retrieved December 10, 2016, from https://mindsetmeter.appspot.com/share/dlmooc

PERTS. (2015b). Our Mission. Retrieved December 12, 2016, from https://www.perts.net/about 
Piaget, J. (1952). The origins of intelligence in children. New York: International Universities Press. https://doi.org/10.1037/11494-000

Sidik, Y. M. (2013). Communication in public administration. Slideshare. Retrieved from http://www.slideshare.net/yhamskiey/communication-in-public-administration-16321538?nex t_slideshow $=1$

Skinner, B. F. (1953). Science and human behavior. New York: Free Press.

Skinner, B. F. (1954). The science of learning and the art of teaching. Harvard Education Review, 24, 86-97.

Stevens, J. (2002). Applied Multivariate Statistics for the Social Sciences (4th ed.). Mahwah, NJ: Lawrence Erlbaum Associates.

Trochim, W. M., \& Donnelly, J. P. (2006). The research methods knowledge base (3rd ed.). Cincinnati, OH: Atomic Dog.

Versland, T. (2009). Self-efficacy development of aspiring principals in education leadership preparation programs. Library Catalog. Retrieved April 4, 2014, from http://isbn.lib.montana.edu/uhtbin/cgisirsi/x/0/0/57/5?user_id=webbz\&password=web19bz\&1 ibrary=BOZEMAN\&searchdata1=1428792\%7BCKEY\%7D

Vygotsky, L. S. (1978). Mind in society: The development of higher psychological processes. Cambridge, MA: Harvard University Press.

Watson, J. B. (1924). Behaviorism. New York: Norton.

Yeo, R. (2005). Revisiting the roots of learning organization: A synthesis of the learning organization literature. The Learning Organization, 12(4), 368-382. http://dx.doi.org/10.1108/ 09696470510599145

\section{Appendix}

Appendix A. Project for Educational Research That Scales (PERTS) survey scale

\begin{tabular}{|l|l|l|l|l|l|l|}
\hline & $\begin{array}{l}\text { Strongly } \\
\text { disagree }\end{array}$ & Disagree & $\begin{array}{l}\text { Somewhat } \\
\text { disagree }\end{array}$ & $\begin{array}{l}\text { Somewhat } \\
\text { agree }\end{array}$ & Agree & $\begin{array}{l}\text { Strongly } \\
\text { agree }\end{array}$ \\
\hline $\begin{array}{l}\text { 1. You can learn new things, but } \\
\text { you can't really change your basic } \\
\text { intelligence/how smart you are. }\end{array}$ & & & & & \\
\hline $\begin{array}{l}\text { 2. Your intelligence is something } \\
\text { about you that you can't change very } \\
\text { much. }\end{array}$ & & & & & & \\
\hline $\begin{array}{l}3 . \quad \text { You have a certain amount of } \\
\text { intelligence, and you really can't do } \\
\text { much to change it. }\end{array}$ & & & & & & \\
\hline
\end{tabular}




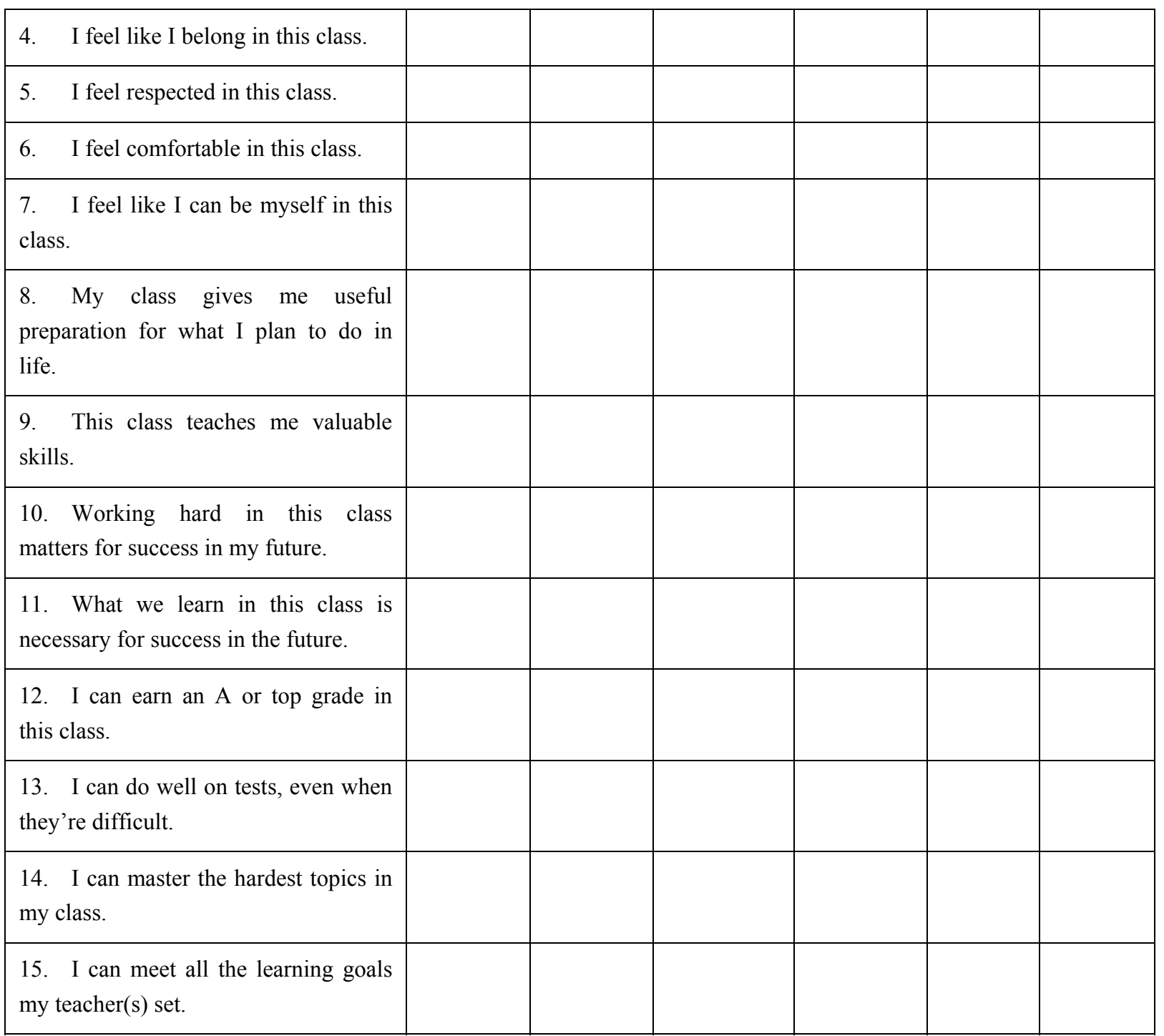

Note. Copyright (C) PERTS, 2015.

\section{Copyright Disclaimer}

Copyright for this article is retained by the author(s), with first publication rights granted to the journal.

This is an open-access article distributed under the terms and conditions of the Creative Commons Attribution license (http://creativecommons.org/licenses/by/3.0/). 